\title{
ПРЕДУПРЕЖДЕНИЕ ТРУДОВЫХ ПРАВОНАРУШЕНИЙ ПРИ РЕГИСТРАЦИИ КОЛЛЕКТИВНЫХ ДОГОВОРОВ
}

\begin{abstract}
АНнотАция. Коллективный договор является главным результатом взаимодействия сторон трудового договора, работников и работодателя, в рамках социального партнерства. С его помощью стороны договариваются о взаимных социально-трудовых обязательствах, превышающих минимум, который закреплен трудовым законодательством. Уведомительная регистрация коллективного договора проводится для проверки на соответствие требованиям трудового законодательства. Важно, чтобы коллективный договор не ухудшал положение работников, гарантированное трудовым законодательством. Очень часто на данном этапе выявляются многочисленные нарушения, которые в дальнейшем способны негативно отразиться на трудовых правах работников. В статье приведены результаты рассмотрения протоколов разногласий, составляемых в процессе регистрации коллективных договоров. Типичные нарушения, выявляемые на данной стадии, сгруппированы по разделам трудового законодательства. Дан обзор наиболее распространенных недостатков юридической техники при составлении коллективных договоров. Проведен анализ нарушений и сделаны обобщающие выводы. Сформулированы функции уведомительной регистрации коллективных договоров.

кЛючЕВЫЕ СЛОВА. Коллективный договор; трудовое законодательство; трудовые отношения; социальное партнерство; трудовое правонарушение; уведомительная регистрация.
\end{abstract}

ИНФОРМАЦИЯ О СТАТЬЕ. Дата поступления 5 июня 2017 г.; дата принятия к печати 11 октября 2017 г.; дата онлайн-размещения 25 октября 2017 г.

A. V. Skavitin

Baikal State University,

Irkutsk, Russian Federation

\section{PREVENTION OF LABOR OFFENCES IN REGISTRATION OF COLLECTIVE LABOR AGREEMENTS}

ABSTRACT. The collective labor agreement is the main result of the interaction of the parties of the employment contract, the employees and the employer, within the social partnership framework. With its help, the parties agree on mutual social and labor obligations that exceed the minimum, which is fixed by the labor legislation. The notifying registration of the collective labor agreement is carried out to verify the compliance with requirements of the labor legislation. It is important that the collective labor agreement does not deteriorate the position of the employees guaranteed by the labor legislation. Numerous offences are revealed very often at this stage, which may negatively affect the labor rights of the employees in the future. The article presents the investigation results of disagreement protocols drawn up in the process of registration of the collective labor agreements. Typical offences identified at this stage are grouped according to the sections of the labor legislation. The review of the most common disadvantages of the legal engineering in formation of the collective labor agreements is given. The analysis of offences is made and general conclusions are drawn. The functions of the notifying registration of the collective labor agreements are defined.

KEYWORDS. Collective labor agreement; labor legislation; labor relations; social partnership; labor offence; notifying registration.

ARTICLE INFO. Received June 5, 2017; accepted October 11, 2017; available online October 25, 2017.

\section{Baikal Research Journal}


Роль коллективного договора, как главного правового акта, регулирующего социально-трудовые отношения на локальном уровне социального партнерства, основана не только на объеме правовых норм, принятых в трудовом законодательстве, но и на оценках самих участников трудовых правоотношений (работников, работодателей, контрольно-надзорных органов, профсоюзов) и была отмечена в исследованиях [1, с. 93-94]. При этом ТК РФ четко обозначает место коллективного договора в системе источников трудового права, определяя в ст. 9 ТК РФ невозможность включения в его текст условий, ограничивающих права или снижающих уровень гарантий работников по сравнению с установленными трудовым законодательством и иными нормативными правовыми актами, содержащими нормы трудового права. Вместе с тем, на практике допускаются множественные попытки включать в коллективные договоры таковые условия. Сама процедура регистрации коллективного договора, закрепленная в ст. 50 ТК РФ, несмотря на внесение поправок в 2006 и 2012 году, по-прежнему вызывает дискуссии. Например, А. Соловьев отмечает оценочный характер формулировки «условия, ухудшающие положение работников по сравнению с трудовым законодательством и иными нормативными правовыми актами, содержащими нормы трудового права», которая, «с одной стороны, задает вектор регистрации коллективных договоров и соглашений, а с другой - создает потенциал социальных конфликтов в социально-трудовой сфере общественных отношений” [2, с. 4-12]. Действительно, каким уровнем компетенции и знаний должен обладать эксперт, выявляющий такие условия в тексте регистрируемого договора? Учитывая, что «прогонять» их следует через все трудовое законодательство и иные правовые акты, содержащие нормы трудового права. И какова вероятность не просмотреть, не заметить, не знать в принципе, не успеть в условиях ограниченности времени ${ }^{1}$ и т.п.? Резонно указывает Апоревич В. на то, что фактически «вопрос, ухудшено ли положение работников в связи с введением в действие коллективного договора, отдан на откуп чиновникам, представляющим интересы органов исполнительной власти местного уровня» [3, с. 27-28].

Уведомительную регистрацию можно отнести к формальным способам оценки качества социально-партнерских актов [4, с. 27-28; 5], в ходе которой оцениваются лишь соответствие включенных в них положений действующему состоянию трудового законодательства, и не дается оценка действительно настоящих социально-трудовых «know-how», сформулированными социальными партнерами. Говоря условно, коллективный договор, положения которого полностью заимствованы из действующего законодательства, успешно пройдет процедуру уведомительной регистрации. Тем не менее, именно на этом этапе выявляются предпосылки возникновения многих трудовых правонарушений. Ведь в соответствии с ч. 2 ст. 50 ТК РФ вступление коллективного договора, соглашения в юридическую силу не зависит от факта их уведомительной регистрации (а правоприменители отмечают, что проверяющие органы зачастую расценивают факт непроведения регистрации как нарушение законодательства о труде и в таком случае организация может быть привлечена к административной ответственности по основаниям, предусмотренным ст. 5.27 КоАП РФ, что подтверждается имеющейся судебной практикой, [6, с. 27]). Следовательно, сколь-угодно долгое время (до факта оспаривания, жалобы, проверки ГИТ и т.п.) включенные в конкретный договор неоднозначные условия будут реально оказывать влияние на трудовые права работников в конкретной организации. В этом смысле процесс регистрации коллективного договора можно рассматривать как крайне важную профилактическую процедуру, в т.ч. предупреждающую вероятность возникно-

${ }^{1} \kappa$ примеру, в Иркутской области Административным регламентом предоставления государственной УсЛУГИ «ПРОВЕДЕНИЕ УВЕДОМИТЕЛЬНОЙ РЕГИСТРАЦИИ КОЛЛЕКТИВНЫХ ДОГОВОРОВ» на правовую оценку коллективного договора дается не более 20 рабочих дней.

\section{Baikal Research Journal}

электронный научный журнал Байкальского государственного университета 
вения коллективного трудового спора [7, с. 67]. Зарубежные правовые системы часто предполагают стадию регистрации коллективных договоров и соглашений, в т.ч. как обязательное условие их юридической силы и исполнения [8, с. 11].

Для анализа нарушений трудового законодательства действующих коллективных договоров была определена случайная выборка коллективных договоров, находящихся в процедуре проверки и уведомительной регистрации ( $n=152$ коллективных договора ${ }^{2}$ ), в которую вошли иркутские организации различных форм собственности и отраслевой принадлежности. Анализ проводился следующим образом: оценивалось количество нарушений по разделам ТК РФ (рис. 1), количество нарушений по статьям и иные нарушения на основе регистрационных листов с замечаниями и предложениями $к$ коллективному договору по итогам проведения экспертизы. Нарушенные нормы трудового законодательства, указанные в регистрационных листах, далее группировались по признаку принадлежности к тому или иному разделу ТК РФ, а внутри разделов - по отдельным главам, внутри глав - по отдельным статьям. Проведенная работа показала, что редко какой коллективный договор на стадии его подготовки социальными партнерами и регистрации избегает выявления недочетов, замечаний и ошибок. Это касается как юридической техники, так и прямых нарушений, включения обязательств, ухудшающих положение работников по сравнению с действующим законодательством.

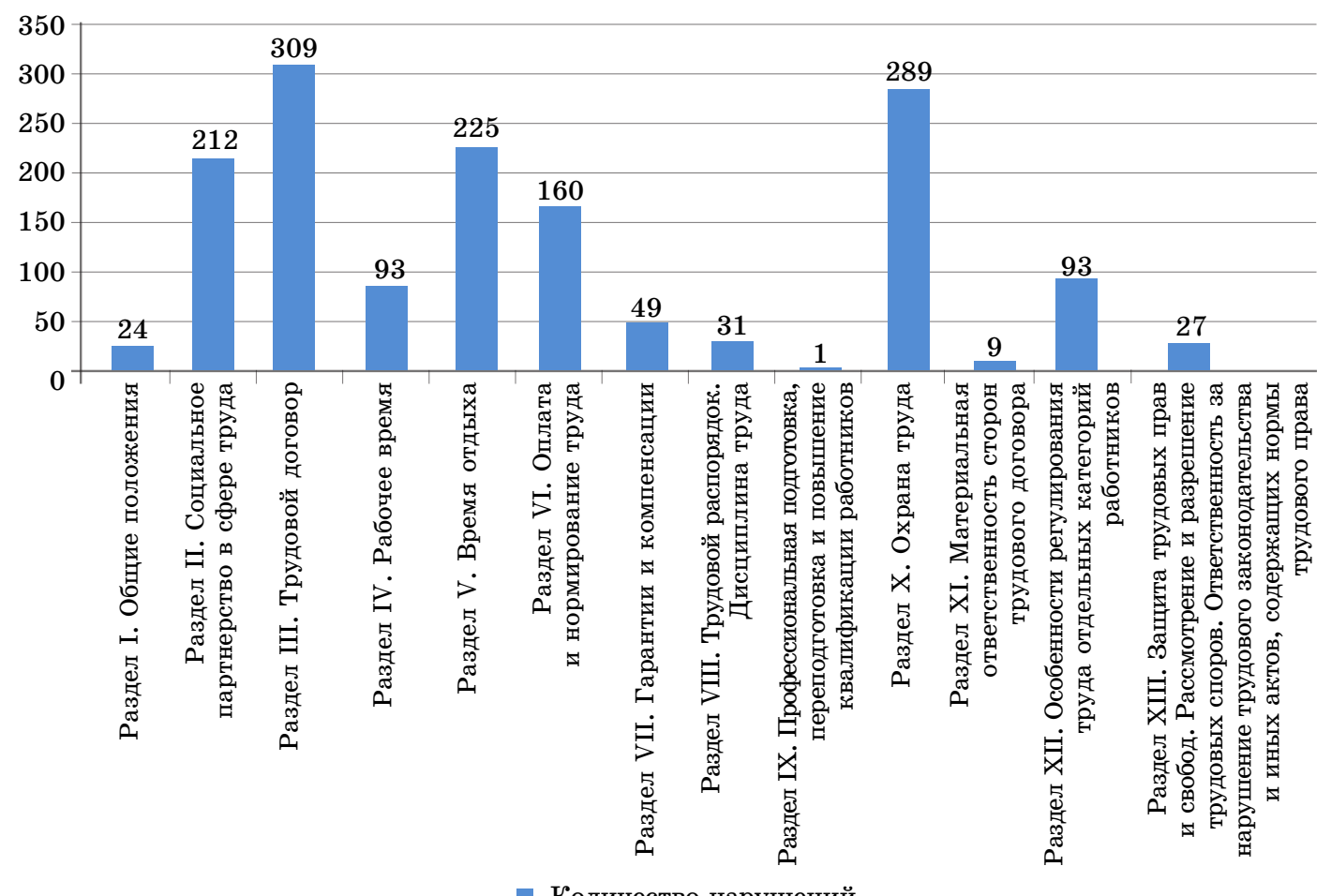

Рис. 1. Нарушения трудового законодательства в стадии регистрации коллективного договора

${ }^{2}$ Руководствуясь ч. 3 ст. 50 ТК РФ, несоответствие и недостатки заключенных коллективных договоров выявляются в ходе проведения их экспертиз. В Иркутске эта процедура закреплена за отделом труда и управления охраной труда департамента закупок, ценового тарифного регулирования и трудовых отношений комитета по бюджетной политике и финансам администрации г. Иркутска.

\section{Baikal Research Journal}


В целом по выборке наибольшее количество замечаний связано с наиважнейшими институтами трудового права - трудовым договором (20\% всех нарушений), охраной труда (19\%), временем отдыха (15\%), социальным партнерством (14\%), оплатой и нормированием труда $(11 \%)$. По всем обследованным 152 договорам выявлено 1552 замечания (в среднем по 10 замечаний на 1 договор), что говорит о достаточной тщательности, с которой проводится экспертиза. Хотя бы один раз зафиксированы нарушения 160 статей ТК РФ (фактически, каждой третьей статьей ТК РФ), из которых только 41 статья нарушена единично, остальные - неоднократно.

Рассмотрим наиболее типичные замечания к текстам коллективных договоров, выявляемых иркутскими экспертами. Из нарушений в сфере социального партнерства самыми распространенными (97 из 212 случаев, или $47 \%$ ) являются нарушения требований ст. 50 ТК РФ, устанавливающей 7-дневный (с момента подписания) срок представления коллективного договора на регистрацию. В каждом четвертом случае (54 из 212) не соблюдены правила пролонгации коллективного договора в нарушении ст. 43 ТК РФ. Бывает, что дата вступления коллективного договора в силу, а также срок его действия не корреспондируется с датой и сроком, указанными на титульном листе договора, это впоследствии способно привести к трудностям определения действия коллективного договора во времени. Принципы социального партнерства, определенные в ст. 24 ТК РФ, также выступают объектом нарушения. Например, подписи сторон «Утверждаю» (работодатель) и «Согласовано (профсоюз), столь привычные на любом другом локальном нормативном акте, на титульном листе коллективного договора будут свидетельствовать о нарушении социально-партнерского принципа равноправия сторон (абз. 1 ч.1 ст. 24 ТК РФ). А принцип реальности обязательств, принимаемых на себя сторонами (абз. 9 ст. 24 ТК РФ), будет поставлен под сомнение, если в договор включена фраза «выполнение финансовых обязательств по настоящему коллективному договору зависит от наличия денежных средств у организации».

Наиболее значительное количество нарушений устанавливается по разделу ТК РФ «Трудовой договор» (см. рис. 2). В качестве типичных нарушений данного раздела ТК РФ проверяющие отмечают следующие ситуации:

- игнорирование выборного органа первичной профсоюзной организации при рассмотрении вопросов, связанных с расторжением трудового договора по инициативе работодателя в соответствии со ст. 82 ТК РФ, допускается в 40 случаях на 309 нарушений по разделу всего, или $13 \%$;

- расширительная трактовка случаев заключения срочных трудовых договоров, ограниченный характер которых закреплен ст. 58 и 59 ТК РФ, отсутствие в срочном договоре причин его заключения на определенный срок (ст. 57 ТК РФ).

- нарушение требований ст. 74 ТК РФ в части, предусматривающей изменение определенных сторонами условий трудового договора по инициативе работодателя (оплаты труда, режима работы, права и обязанности работника и др.) с предупреждением работника о предстоящих изменениях за два месяца и только с его письменного согласия, в т.ч. через попытки установления иных (меньших) сроков уведомления работников (из 309 замечаний по разделу на подобные пришлось 30 , или $11 \%$ );

- установление требований работодателя о предъявлении лицом, поступающим на работу, документов, не предусмотренных ст. 65 ТК РФ, иными федеральными законами, указами Президента РФ и постановлениями Правительства РФ (к примеру, свидетельства об ИНН, заключения о состоянии здоровья, справки о последнем занятии и т.п.) - 30 замечаний из 309 , или $10 \%$;

- нарушение требований ст. 68 ТК РФ, в соответствии с которой прием на работу оформляется приказом (распоряжением) работодателя на основании заклю-

\section{Baikal Research Journal}

электронный научный журнал Байкальского государственного университета 
ченного трудового договора (а не заявления) - 27 замечаний из 309 по разделу в целом, или $9 \%$

- иногда встречаются ошибки в установлении испытательного срока при приеме на работу в соответствии со ст. 70 ТК РФ (превышающие 3 и 6 месяцев в отдельных случаях), а также применение испытания к категориям работников, свободным от установления такового - 18 замечаний из 309 по разделу в целом, или $6 \%$.

\title{
Передача персональных данных работника (ст. 88) $\mid 1$ \\ Общий порядок оформления прекращения трудового договора (ст. 84.1)
}

Прекращение трудового договора вследствие нарушения установленных настоящим Кодексом или иным федеральным законом правил заключения трудового договора Обязательное участие выборного органа первичной профсоюзной организации в рассмотрении вопросов, связанных с расторжением трудового договора по инициативе работодателя (ст 82)

Расторжение трудового договора по инициативе работодателя (ст. 81) Расторжение трудового договора по инициативе работника (по собственному желанию) (ст. 80) Общие основания прекращения трудового договора (ст. 77) 2 Отстранение от работы (ст. 76) 3

Изменение определенных сторонами условий трудового договора по причинам, связанными с изменением организационных или технологических условий труда (ст. 74) Перевод работника на другую работу в соответствии с медецинским заключением (ст. 73) Временный перевод на другую работу (ст 72.2)

Изменение определенных сторонами условий трудового договора (ст. 72) Результат испытания при приеме на работу (ст. 71) 1

Испытание при приеме на работу (ст. 70)

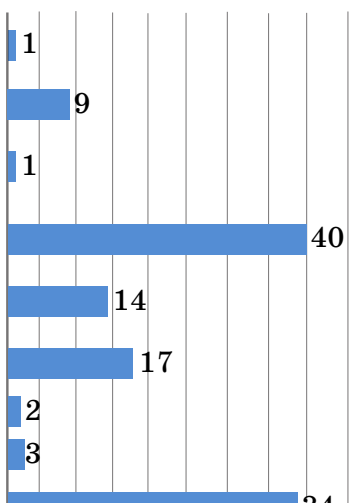

\author{
3
1
}

Медицинский осмотр (обследование) при заключении трудового договора (ст. 69)

Оформление приема на работу (ст. 68)

Форма трудового договора (ст. 67)

Трудовая книжка (ст. 66)

12

Документы, предъявляемые при заключении трудового договора (ст. 65)

Гарантии при заключении трудового договора (ст. 64)

Вступление трудового договора в силу (ст. 61)

Запрещение требовать выполнение работы, не обусловленной трудовым договорам (ст. 60)

Срочный трудовой договор (ст. 58)

$$
\text { Ст } 57 \text { изм. }
$$

Содержание трудового договора (ст. 57)

Понятие трудового договора. Стороны трудового договора (ст. 56) 1

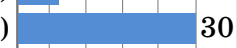

- Количество нарушений

$0 \quad 51015202530354045$

Рис. 2. Нарушения по разделу III ТК РФ «Трудовой договор»

Типичными нарушениями требований законодательства о рабочем времени выступают вопросы регулирования сверхурочной работы, сменной работы и неполного рабочего времени - из 93 замечаний на долю этих трех категорий пришлось 66 (71\%). В некоторых коллективных договорах перечислены не все категории работников, которым по закону обязана быть установлена сокращенная продолжительность рабочего времени, либо не конкретизирована в часах продолжительность этого времени (ст. 92 ТК РФ). Встречаются ситуации, когда социальные партнеры не конкретизируют в тексте коллективного договора категории работников, которых не допускается привлекать к сверхурочной работе, в нарушение ч. 5 ст. 99 ТК РФ.

\section{Baikal Research Journal}


Из 225 замечаний, связанных с регулированием времени отдыха, типичными нарушениями выступают следующие:

- нарушения ст. 123 ТК РФ в части, предусматривающей утверждение графика отпусков работодателем с учетом мнения выборного профсоюзного органа данной организации не позднее чем за две недели до наступления календарного года, а также извещение под роспись до начала отпуска (ч. 3 ст.123 ТК РФ) $-25 \%$ замечаний по разделу в целом, или 56 из 225 ;

- предоставление отпусков без сохранения заработной платы иногда прописывается, как мера предотвращения сокращений, либо как бесплатная альтернатива организации простоя по вине работодателя, что противоречит смыслу ст. 128 TК РФ, в соответствии с которой продолжительность такого отпуска определяется по соглашению сторон трудового договора $-22 \%$ замечаний по разделу, или 50 из 225 ; также по данной статье производятся замечания, если социальные партнеры в тексте договора используют формулировку "работодатель имеет право», вместо «работодатель обязан», когда речь идет о предоставлении такого отпуска отдельным категориям работников, указанным в ч. 2 ст. 128 ТК РФ;

- нарушения требований ст. 126 ТК РФ, в части запрета денежной компенсаций отпуска отдельным категориям работников (например, при увольнении за неиспользованные отпуска беременным женщинам - 8 \%, или 17 из 225 замечаний по разделу;

- не всегда учтены требования ст. 125 ТК РФ, когда неиспользованная часть отпуска должна быть присоединена к отпуску за следующий рабочий год при отзыве работника из отпуска $-7 \%$, или 15 из 225 по разделу.

Самые распространенные нарушения в разделе оплата и труда и нормирование труда связаны с порядком, местом и сроками выплаты заработной платы. На 160 замечаний, выявленных экспертами по данному разделу, половина, или $46 \%$, приходится на несоответствие предписаниям ст. 136 ТК РФ, когда в коллективном договоре не указываются конкретные сроки выплаты заработной платы или включались условия, предусматривающие выплату заработной платы один раз в месяц в нарушение требований ч. 6 ст. 136. Иногда в коллективных договорах используются термины, которые не корректны по отношению к ст. 129 ТК РФ, например, «бюджетная заработная плата», «ставка заработной платы», что следует отнести к недостаткам юридической техники при составлении текста договора. Встречаются ситуации, когда в коллективном договоре не конкретизирован размер оплаты труда в выходные и нерабочие дни (ч. 2 ст. 153 ТК РФ).

Положения трудовых или коллективных договоров должны предусматривать оплату работы в выходные и праздничные дни, так как ст. 153 ТК РФ установлен лишь минимальный размер доплаты за работу в праздничный или выходной день (но не менее чем в двойном размере). Следовательно, работодатель может оплачивать работу в выходные и праздничные дни и в большем размере. Поэтому, при уведомительной регистрации, как правило, проверяющие обращают внимание на отсутствие конкретизации размеров таковой оплаты. В нашем исследовании подобные замечания касались 18 договоров из всех обследованных 152 .

Наибольшее количество замечаний в сфере гарантий и компенсаций, 18 из 49, или $37 \%$ по разделу в целом, пришлось на нарушения требований ст. 180 ТК РФ, в соответствии с которой о предстоящем увольнении в связи с сокращением численности или штата работников организации работодатель обязан предупредить работников персонально и под расписку не менее чем за 2 месяца до увольнения. Относительно часто (в 14 коллективных договорах) не в полной мере или вообще не учтены требования ст. 179 ТК РФ, закрепляющий четкую последовательность критериев при определении кандидатов на сокращение

\section{Baikal Research Journal}


численности, которую работодатель не может нарушить. Например, положение, при котором преимущественным правом на оставление на работе обладает работник, чей стаж в организации больше, а производительность труда ниже, полностью искажает смысл ст. 179 ТК РФ.

Нормы трудового законодательства по вопросам трудового распорядка и дисциплины труда на стадии уведомительной регистрации коллективного договора нарушаются редко. Из всей совокупности обследованных договоров на долю этого раздела пришлось 31 замечание. Как правило, во многих проверенных организациях зачастую вообще отсутствовали правила внутреннего трудового распорядка (ст. 190 ТК РФ), большинство нарушений (14 случаев) связаны с порядком применения дисциплинарных взысканий, установленных в ст. 193 ТК РФ. Изредка в текстах договоров встречаются устаревшие обозначения взысканий («строгий выговор», к примеру).

Нарушения в области охраны труда - вторые по распространенности в нашем исследовании, после раздела «Трудовой договор», встречающиеся практически в каждом поданном на регистрацию коллективном договоре, причем неоднократно. Согласно ч. 2 ст. 22 и ч. 1 ст. 212 ТК РФ обязанность по охране труда возложена на работодателя. Нарушения в области охраны труда в основном связаны с несоблюдением обязанностей работодателя, предусмотренных ч. 2 ст. 212 ТК РФ (128 замечаний, или $44 \%$ по разделу в целом). К данным видам нарушений можно отнести обязательства работодателя:

- по приобретению и выдачи за счет собственных средств спецодежды, специальной обуви и других средств индивидуальной защиты, смывающих и обезвреживающих средств;

- по обучению безопасным методам и приемам выполнения работ, оказанию первой помощи пострадавшим на производстве, стажировки на рабочем месте и проверки знания требований охраны труда;

- по проведению специальной оценки условий труда, по финансированию мероприятий по улучшению условий труда (ст. ст. 212,226 ТК РФ);

- по проведению за счет собственных средств обязательного предварительного (при поступлении на работу) и периодического медицинского осмотра (обследования).

В ряде коллективных договоров допускалось, что для расчета суммы денежных средств, направляемых на мероприятия по улучшению охраны труда, можно применять эксплуатационные расходы. Это противоречит требованиям ст. 226 ТК РФ. Также не редки ситуации, когда в договоре не конкретизирован размер средств на мероприятия по охране труда (ч. 3 ст. 226 ТК РФ), который должен осуществляться в размере 0,2 \% суммы затрат на производство продукции (работ, услуг). В целом, на нарушения по ст. 226 ТК РФ пришлось 31 замечание из 289 по разделу в целом, или $11 \%$ ).

В области регулирования труда отдельных категорий работников типичные замечания к содержанию регистрируемых договоров чаще всего сводятся к соблюдению гарантий при увольнении женщин и лиц с семейными обязанностями, ст. 261 ТК РФ (19 замечаний), а также лиц до 18 лет, ст. 269 ТК РФ (12 замечаний). Не всегда учитываются законные права указанных категорий работников при направлении в служебные командировки, привлечение к сверхурочным работам, работе в ночное время, в выходные и нерабочие праздничные дни - на долю замечаний по ст. 259 и 268 ТК РФ пришлось $18 \%$ из 93 замечаний по разделу в целом.).

Очень часто стороны социального партнерства допускают невнимательность при формулировании норм коллективного договора и используют утратившие силу законодательные и нормативные правовые акты в качестве обоснований закрепляемых норм. Анализ показал также, что часто не учитываются требования

\section{Baikal Research Journal}

электронный научный журнал Байкальского государственного университета 
других, помимо ТК РФ, законодательных и нормативно-правовых актов, особенно по вопросам установления дополнительных отпусков, норм выдачи средств индивидуальной защиты, смывающих и обезвреживающих веществ.

Отдельно стоит сказать и об огрехах юридической техники при формулировании отдельных положений коллективного договора, повторяющиеся из года в год и неоднократно отмечающиеся исследователями $[9 ; 10]$. Так, в коллективных договорах, из текста в текст нередко буквально "кочуют» устарелые, отмененные, либо упрощенные и, соответственно, некорректные для использования день термины «общество», «компания», «администрация», «профком», «сотрудники», «трудовой коллектив», «контракт», «существенные условия труда», «систематическое нарушение трудовой дисциплины», «административный отпуск», «отпуск без содержания», «строгий выговор» и т.п., т.е. либо тех понятий, которые содержались еще в КЗоТ РФ, либо попросту терминов из профессионального жаргона кадровиков.

Таким образом, ознакомившись подробно с содержанием процедуры уведомительной регистрации коллективных договоров, масштабом и характером выявляемых замечаний, можно выделить ряд функций, которые выполняет данная процедура в общем механизме социального партнерства:

Защитная функция. Стороны социального партнерства, как правило склонны исключать выявленные замечания из текста коллективного договора, но даже если таковые остаются, то будучи обнаруженными и озвученными в ходе уведомительной регистрации вероятность реализации на практике таких положений коллективного договора резко снижается. Процедура регистрации защищает целые коллективы от закрепления норм, ухудшающих положение работников по сравнению с трудовым законодательством и иными нормативными актами, содержащими нормы трудового права.

Превентивная (предупредительная) функиия. Орган, осуществляющий регистрацию, и выявляющий нарушения трудового законодательства, содержащиеся в только что подписанном коллективном договоре, результатами своей экспертизы фактически обязывает социальных партнеров обратить внимание на выявленные замечания и оперативно устранить их. Этим предупреждаются нарушения трудовых прав работников в дальнейшем, в ходе реализации положений коллективного договора, предупреждается допущение аналогичных ошибок при подготовке других локальных нормативных актов.

Учетная функиия. Государство, в лице органов, осуществляющих уведомительную регистрацию, ведет учет заключенных коллективных договоров, в результате чего становится возможным установить охват коллективно-договорным регулированием на территории, его отраслевую структуру, временной горизонт действия социально-партнерских актов.

Контрольная функция. Орган по труду (специалист) органа местного самоуправления, ответственного за регистрацию коллективных договоров, как правило, имеет полномочие в дальнейшем осуществлять пострегистрационный контроль за реализацией коллективного договора в течение всего срока его действия, в том числе за неприменением условий, ухудшающих положение работников по сравнению с трудовым законодательством и иными нормативными актами, содержащими нормы трудового права.

Инфорлационная функция. Посредством экспертизы коллективного договора и выявления замечаний орган, осуществляющий регистрацию, доводит до сторон социального партнерства информацию о наиболее актуальных формулировках трудоправовых норм, изменениях трудового законодательства, отмене ранее действовавших норм трудового права, чем способствует росту правовой грамотности среди работодателей и представителей работников.

\section{Baikal Research Journal}

электронный научный журнал Байкальского государственного университета 


\section{Список использованной литературы}

1. Трансформация системы управления человеческими ресурсами региона в условиях экономического кризиса: проблемы и тенденции / под ред. М. А. Винокурова, Т. Г. Озерниковой. - Иркутск : Изд-во БГУЭП, 2010. - 360 с.

2. Соловьев А. В. Процедура регистрации коллективного договора: сущность и проблемы / А. В. Соловьев // Кадровик. - 2007. - № 10. - С. 4-12.

3. Апоревич В. Н. Правовые проблемы процедуры регистрации коллективного договоpa / В. Н. Апоревич // Современные проблемы и пути их решения в науке, транспорте, производстве и образовании 2010. Сборник научных трудов по материалам международной научно-практической конференции, 20-27 декабря 2010 года. Том 21. Юридические и политические науки. - Одесса: Черноморье, 2010. - Т. 21. - С. 27-31.

4. Скавитин А. В. Оценка качества коллективных договоров / А. В. Скавитин // Персонал МИКС. - 2006. - № 9-10. - С. 27-31.

5. Скавитин А. В. Коллективный договор: возможности в условиях кризиса / А. В. Скавитин // Кадровик. - 2010. - № 1. - С. 26-33.

6. Горшкова Л. Л. Сложные вопросы применения трудового законодательства / Л. Л. Горшкова // Бухгалтерский учет в бюджетных и некоммерческих организациях. 2012. - № 15. - С. 24-28.

7. Елец С. А. Способы предупреждения возникновения коллективных трудовых споров / С. А. Елец // Молодой ученый. - 2016. - № 6-6(110) - С. 66-67.

8. Lawrence, S.; Ishikawa, J. Social Dialogue Indicators, Trade union membership and collective bargaining coverage: Statistical concepts, methods and findings / Geneva, International Labour Office, 2005 http://www.ilo.org/wcmsp5/groups/public/---dgreports/--integration/documents/publication/wcms_079175.pdf.

9. Скавитин А. В. Коллективный договор: ошибки и нарушения / А. В. Скавитин // Кадровик. - 2010. - № 4-2. - С. 75-78.

10. Соловьев А. В. Коллективный договор, или как достичь успеха в проведении коллективно-договорной кампании / А. В. Соловьев - М. : «Альфа-Пресс», 2007. — 188 с.

\section{References}

1. Vinokurov M. A., Ozernikova T. G. (eds). Transformatsiya sistemy upravleniya chelovecheskimi resursami regiona $v$ usloviyakh ekonomicheskogo krizisa: problemy $i$ tendentsii [Transformation of regional human resource management system in terms of economic crisis: problems and trends]. Irkutsk, Baikal State University of Economics and Law Publ., 2010. 360 p.

2. Solov'ev A. V. Collective labor agreement registration procedure: essence and problems. Kadrovik = Personnel Officer, 2007, no. 10, pp. 4-12. (in Russian).

3. Aporevich V. N. Legal problems of collective labor agreement registration procedure. Sovremennye problemy $i$ puti ikh re-sheniya $v$ nauke, transporte, proizvodstve $i$ obrazovanii 2010. Sbornik nauchnykh trudov po materialam mezhdunarodnoi nauchno-prakticheskoi konferentsii, 20-27 dekabrya 2010 goda. Tom 21. Yuridicheskie i politiche-skie nauki. [Present-day problems and ways of their solution in science, transport, production and education 2010. Collection of Scientific Papers on Materials of International Science and Practice Conference, December 20-27, 2010. Volume 21. Juridical and Political Sciences]. Odessa Chernomor'e, 2010, vol. 21. pp. 27-31. (in Russian).

4. Skavitin A. V. Assessing quality of collective labor agreements. Personal MIKS $=$ Per sonal MIKS, 2006, no. 9-10, pp. 27-31. (in Russian).

5. Skavitin A. V. Collective labor agreement: opportunities in terms of crisis. Kadrovik= Personnel Officer, 2010, no. 1, pp. 26-33. (in Russian).

6. Gorshkova L. L. Complicated issues of using labor legislation. Bukhgalterskii uchet $v$ byudzhetnykh i nekommerche-skikh organizatsiyakh = Accounting in Budget and Non-Commercial Organizations, 2012, no.15, pp. 24-28. (in Russian).

7. Elets S. A. Ways of preventing uprisals of collective labor disputes. Molodoi uchenyi= Young Scientist, 2016, no. 6-6(110), pp. 66-67. (in Russian).

8. Lawrence S., Ishikawa J. Social Dialogue Indicators, Trade union membership and collective bargaining coverage: Statistical concepts, methods and findings . Geneva, International

\section{Baikal Research Journal}


Labour Office, 2005 Available at: http://www.ilo.org/wcmsp5/groups/public/---dgreports/--integration/documents/publication/wcms_079175.pdf.

9. Skavitin A. V. Collective labor agreement: mistakes and irregularities. Kadrovik= Personnel Officer, 2010, no. 4-2, pp. 75-78. (in Russian).

10. Solov'ev A. V. Kollektivnyi dogovor, ili kak dostich' uspekha v pro-vedenii kollektivno-dogovornoi kampanii [Collective labor agreement, or how to succeed in running a collective-agreement campaign]. Moscow «Al>fa-Press» Publ., 2007. 188 p.

\section{Информация об авторе}

Скавитин Алексей Васильевич - кандидат экономических наук, доцент, декан факультета управления человеческими ресурсами, Байкальский государственный университет, 664003, г. Иркутск, ул. Ленина, 11, e-mail: skavitin2000@mail.ru.

\section{Author}

Alexey V. Skavitin - PhD in Economics, Assistant Professor, Dean of Human Resources Management Department, Baikal State University, 11, Lenin str., Irkutsk, 664003; e-mail: skavitin2000@mail.ru.

\section{Для цитирования}

Скавитин А. В. Предупреждение трудовых правонарушений при регистрации коллективных договоров / А. В. Скавитин // Baikal Research Journal. — 2017. — T. 8, № 3. DOI: $10.17150 / 2411-6262.2017 .8(3) .21$.

\section{For Citation}

Skavitin A.V. Prevention of Labor Offences in Registration of Collective Labor Agreements. Baikal Research Journal, 2017, vol. 8, no. 3. DOI: 10.17150/2411-6262.2017.8(3).21. (In Russian).

\section{Baikal Research Journal}

